\section{Kangarooed duodenum: Intraluminal duodenal diverticulum}

We present a case of intraluminal duodenal diverticulum (IDD) ${ }^{1}$ which presented as upper gut obstruction.

\section{Case Report}

A 26 year old male presented with abdominal pain for 6 months, with history of bilious vomiting since 3 months. Basic investigations including ultrasound abdomen and liver function tests were found to be normal. Upper gastrointestinal endoscopy revealed a globular lesion in the distal second part of duodenum with a small opening in it with some bilious material in the distal second part of duodenum (Figure 1). At this point it looked like an eccentrically placed ampulla with intraduodenal type 3 choledochal cyst (choledochocele) but while pulling the scope back we were able to make out a separate ampullary opening in the usual position which pointed against choledochocele. We then injected contrast through the small opening in the lesion, the contrast was filling in the cavity into the duodenal lumen and this confirmed that it was an IDD ( Figure 2). Barium and CT abdomen were done and showed classical "halo sign" suggestive of IDD (Figure 3,4). Patient underwent duodenotomy and excision of the diverticulum and asymptomatic post operatively.

\section{Discussion}

IDD is otherwise termed as Windsock web which is a very rare congenital condition in the adult..,3 Usually originates in the second portion of duodenum and can project distally even up to 4th part of duodenum. Less than 100 cases have been reported in literature so far. In $40 \%$ of patients it may be associated with other congenital anomalies like annular pancreas and Down's syndrome. It is a result of failure of full recanalization and a membranous tissue stretching across a portion of the duodenal lumen, so the peristaltic movement of the

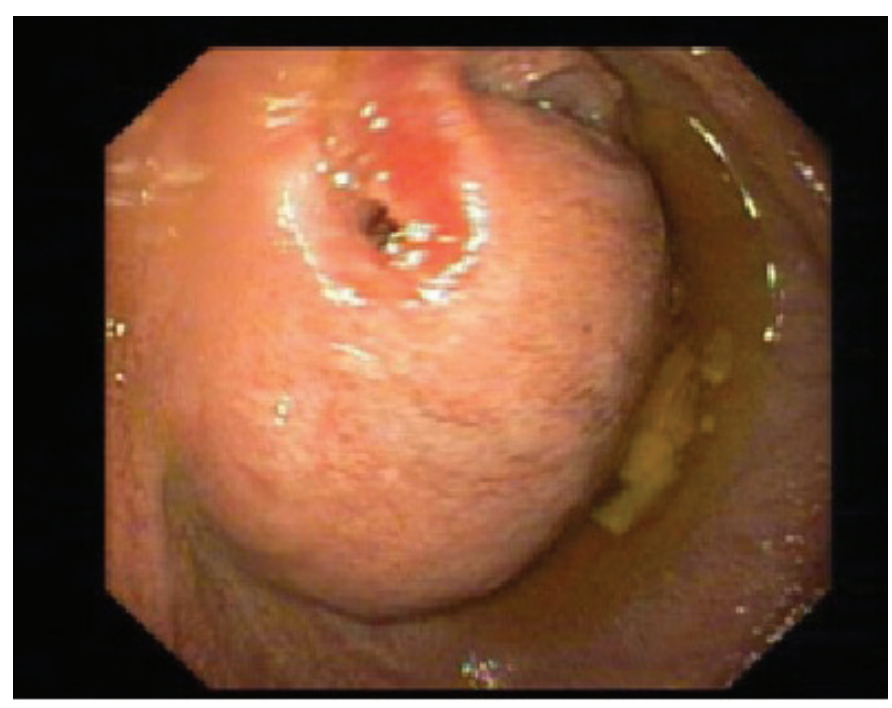

Figure 1: Endoscopic image showing a globular lesion in the second part of duodenum.
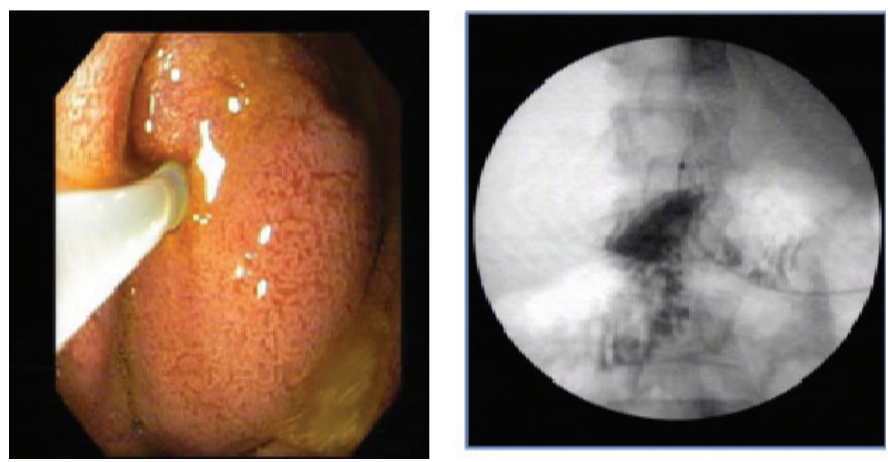

Figure 2: Injecting contrast through the opening in the lesion and flouroscopic image showing filling up of contrast into the duodenal lumen.

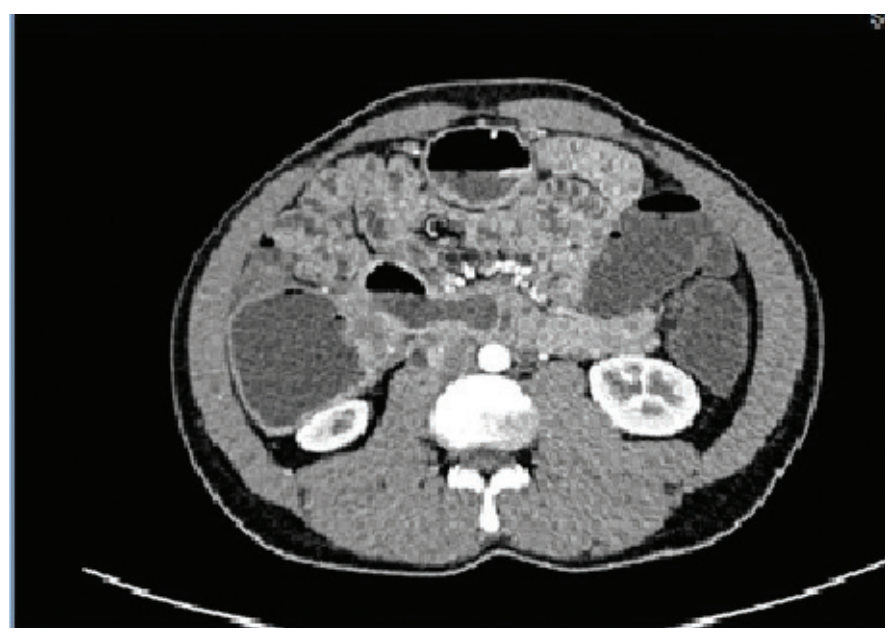

Figure 3: CECT abdomen showing a dilated stomach and dilated second part of duodenum with IDD. 


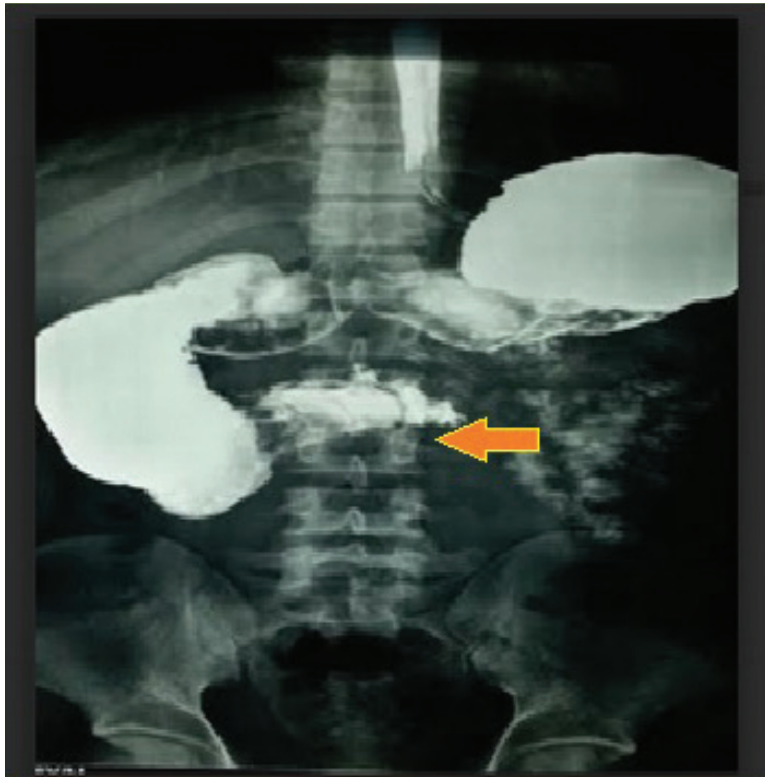

Figure 4: Barium meal series showing a halo sign suggestive of IDD.

duodenum leads to formation of a sac like structure which is the IDD. The median age of presentation is $3 \mathrm{rd}$ to 4 th decade. Most common presentation is pain abdomen followed by partial obstruction, pancreatitis and upper UGI bleed. ${ }^{4}$ The usual site of IDD is proximal to ampulla in $52 \%$, at the ampullary level in $30 \%$ and distal to ampulla in $18 \%$. The close differentials are choledochocele and duplication cysts which can be differentiated by imaging studies where the choledochocele will be continuous with bile duct and duplication cyst will not take up barium/ contrast as it is not connected with duodenal lumen. Endoscopic management by snare technique and needle knife resection has been proposed as this is not a true diverticulum and has duodenal mucosa covered on both sides, but always a careful delineation of ampullary, bile duct and pancreatic duct anatomy is very important before endoscopic management as this can result in permanent bile duct injuries. ${ }^{5}$ Our case presented with partial duodenal obstruction and hence we offered a surgical resection of the diverticulum after which he became asymptomatic. As it resembled a kangaroo's pouch we named it kangarooed duodenum.

\author{
SEKAR $^{2}$ \\ KUMARAGURUBARAN ${ }^{3}$ \\ ${ }^{1}$ Department of Medical Gastroenterology, Rajiv Gandhi \\ Government General Hospital, Chennai. \\ ${ }^{2}$ Radiology, ${ }^{3}$ Surgery, Billroth Hospital, Chennai. \\ Correspondence: Ila Varasi \\ Email: iloomd09@gmail.com
}

\section{References}

1. Nakamura M, Nishikawa J, Hashimoto S, Takeo S, Miura O, Sakaida I. Gastrointesintal: rare congenital abnormality of the duodenum: intraluminal duodenal diverticulum. J Gastroenterol Hepatol. 2014;29(5):893.

2. Matsushita M, Uchida K, Nishio A, Okazaki K. Differential diagnosis of intraduodenal cystic lesions: choledochocele, duodenal duplication cyst, or intraluminal duodenal diverticulum? Gastrointest Endosc. 2010;71(1):219; author reply 219-20.

3. Kapuria D, Jonnalagadda S. The "Windsock Sign": Intraluminal Duodenal Diverticulum. Clin Gastroenterol Hepatol. 2016;14(8):e93-4.

4. Anand V, Provost J, Bakr M, Bach C, Merchant P, Brown C, Gruss C. Two Cases ofIntraluminal "Windsock" Diverticula Resulting in Partial Duodenal Obstruction. ACG Case Rep J. 2016;28;3(4):e135.

5. Law R, Topazian M, Baron TH. Endoscopic treatment of intraluminal duodenal("windsock") diverticulum: varying techniques from five cases. Endoscopy. 2012;44(12): 1161-4. 